\title{
PENGARUH PIJAT PERINEUM SELAMA MASA KEHAMILAN TERHADAP KEJADIAN RUPTURA PERINEUM SPONTAN DI PMB SHINTA NUR ROCHMAYANTI, SSiT., M.Kes
}

\author{
Shinta Nur Rochmayanti ${ }^{1}$, Kholifatul Ummah ${ }^{2}$ \\ ${ }^{1,2}$ Fakultas Ilmu Kesehatan program Studi D-III Kebidanan \\ Universitas Dr.Soetomo Surabaya \\ Email:chik_ayou@yahoo.co.id,ummahifa@gmail.com
}

\begin{abstract}
Some of the factors that cause perineal rupture consist of maternal factors, fetal factors, and helper factors. A method of reduce perineal rupture is a perinel massage to promote heatlh, blood flow and elasticity of the perineum. Based on preliminary study at PMB Shinta Nur Rochmayanti, SSiT., M.Kes from June to September of 2017 there were 20 births per month, and $70 \%$ had spontaneous birthrate while $30 \%$ had no perineal rupture. The purpose of this study was to determine the effect of perineal massage during pregnancy on the incidence of Rupture Perineum during delivery at the Midwives Practice Midwife Shinta Nur Rochmayanti, SSiT., M.Kes year 2018. The objektive of this study was to determine the effect of perineal massage on the incidence of perineal rupture in pregnant period during childbirth in independent practice of midwifery in PMB Shinta Nur Rochmayanti, SSiT., M.Kes year 2018. This study is Quasi Experimental study with Post Test Only Control Group Design method. The study was conducted in midwife Mandiri Practice (PMB) Shinta Nur Rochmayanti, SSiT., M.Kes Surabaya in 2018 with subject of 28 pregnant women 36 weeks pregnancy consisting of 14 intervention group and 14 control group. The study was conducted from December 2017 until April 2018, then the data were analyzed by Chi Square test. The incidence of Rupture Perineum in the intervention group after perineal massage was only $14,3 \%$ while in the control group $64,3 \%$. The results showed that there was an effect of perineal massage during pregnancy on the incidence of perineum rupture $(\mathrm{p}<0.05)$. This study concluded that perineal massage during pregnancy affects the incidence of perineal rupture at delivery.
\end{abstract}

Keywords : perineal massage, pregnant periode, perineal rupture

\section{PENDAHULUAN}

Kematian ibu merupakan kematian yang terjadi pada masa kehamilan, persalinan dan nifas oleh sebab tertentu.Indonesia berada di peringkat ketiga tertinggi untuk Angka Kematian Ibu di Negara ASEAN. Peringkat pertama yaitu Laos dengan 470 / 100.000 kelahiran hidup sedangkan terendah yaitu
Singapura dengan $3 / 100.000$ kelahiran hidup.

Penyebab kematian dan kesakitan ibu di Indonesia telah dikenal sejak dahulu dan sampai sekarang tidak berubah banyak. Berdasarkan SDKI 2012, rata-rata angka kematian ibu (AKI) tercatat mencapai 359 per 100 ribu kelahiran hidup. Rata-rata kematian ini jauh melonjak di banding hasil SDKI 2007 yang mencapai 228 per 100 
ribu dan jauh dari target pemerintah yang tertuang dalam MDGs bahwa AKI ditahun 2015 ditargetkan turun menjadi 105 per 100 ribu kelahiran hidup (Depkes RI: 2009).

90\% penyebab kematian ibu terjadi pada saat persalinan.Perdarahan post partum sebagai penyebab utama yaitu menyumbang sebesar $40 \%$. Perdarahan post partum terjadi diantaranya karena adanya robekan jalan lahir atau perineum. Laserasi perineum atau Robekan jalan lahir merupakan penyebab kedua dari perdarahan post partum setelah atonia uteri, hal ini sering terjadi pada primigravida karena pada primigravida perineum masih utuh, belum terlewati oleh kepala janin sehingga akan mudah terjadi robekan perineum (Manuaba IBG, 2005, 15: 157).

Berdasarkan studi pendahuluan di PMB Shinta Nur Rochmayanti, SSiT., M.Kes pada bulan juni sampai dengan bulan September tahun 2017 rata-rata perbulan terdapat 20 persalinan, dan $70 \%$ yang mengalami robekan jalan lahir spontan sedangkan $30 \%$ tidak mengalami robekan perineum. Semua ibu hamil dan yang bersalin di PMB Shinta Nur Rochmayanti, SSiT., M.Kes belum terpapar pijat perineum dikarenakan masih belum dilaksanakannya kelas ibu hamil secara rutin.

Berdasar latar belakang tersebut penulis tertarik untuk meneliti "Pengaruh pijat perineum selama masa kehamilan terhadap kejadian rupture perineum spontan".

\section{PERUMUSAN MASALAH}

Berdasarkan rumusan latar belakang masalah diatas maka dirumuskan masalah penelitian adalah "Apakah ada pengaruh pijat perineum selama masa kehamilan terhadap kejadian rupture perineum spontan di PMB Shinta Nur Rochmayanti, SSiT., M.Kes ”

\section{TUJUAN PENELITIAN}

1. Tujuan Umum

Untuk mengetahui pengaruh pijat perineum selama masa kehamilan terhadap kejadian rupture perineum spontan di PMBShinta Nur Rochmayanti, SSiT., M.Kes

2. Tujuan Khusus

a. Untuk mengetahui karakteristik responden

b. Untuk mengidentifikasi kejadian ruptur perineum setelah dilakukan pemijatan perineum pada kelompok intervensi

c. Untuk mengidentifikasi kejadian ruptur perineum pada kelompok control

d. Mengidentifikasi pengaruh pijat perineum selama masa kehamilan terhadap kejadian rupture perineum spontan di Shinta Nur Rochmayanti, SSiT., M.Kes

\section{MANFAAT PENELITIAN}

1. Bagi Praktek Pelayanan Kebidanan

Hasil penelitian yang diperoleh dapat menjadi sumber pengetahuan dan strategi bagi bidan dalam memberikan asuhan kebidanan pada ibu hamil dan asuhan saying ibu

2. Bagi Peneliti

Peneliti diharapkan dapat memberikan pengetahuan yang berharga dan mengasah pola piker masyarakat, sehingga dapat menerapkan pengalaman ilmiah yang diperoleh untuk 
peneliti di masa yang akan datang

3. Bagi Pendidikan Kebidanan

Penelitian ini sangat berguna untuk menambah wawasan cara ilmu pengetahuan dan sebagai bahan penerapan ilmu kebidanan secara langsung pada masyarakat.

\section{DESAIN PENELITIAN}

Desain yang digunakan dalam penelitian ini adalah quasi eksperimen yaitu rancangan yang berupaya untuk mengungkapkan efektivitas dengan cara melibatkan kelompok control disamping kelompokeksperimen

(Nursalam,2003, hlm 89) dengan rancangan post test only control group design.

Rancangan penelitian dapat digambarkan sebagai berikut :

\begin{tabular}{clc}
\hline Kelompok & \multicolumn{1}{c}{ Perlakuan } & $\begin{array}{c}\text { Post }- \\
\text { test }\end{array}$ \\
\hline Kelompok 1 & Diberikan & Test X \\
Kelompok 2 & Tidakdiberikan & Test Y \\
\hline
\end{tabular}

Keterangan :

Tabel 4.1 .Desainpenelitian

Kelompok1 :subjek (ibu Hamil) perlakuan

Kelompok2 :subjek (ibu Hamil) kontrol

\section{POPULASI DAN SAMPEL}

Populasi dalam penelitian ini adalah seluruh ibu hamil dengan usia kehamilan mulai dari 36 minggu di PMB. Shinta Nur Rochamayanti, SSiT.,M.Kes Surabaya.

Sampel Jumlah sampel dihitung dengan menggunakan rumus uji hipotesis satu sampel tunggal untuk estimasi proporsi suatu populasi terhadap rerata dua populasi independen. Proporsi kedua kelompok adalah 0,044. Berdasarkan rumus tersebut, diperoleh jumlah sampel sebesar 16 orang, ditambah droup out $10 \%$ menjadi 18 orang.

\section{TEMPAT DAN WAKTU PENELITIAN}

Tempat penelitian dilakukan di PMB Shinta Nur Rochmayanti, SSiT.,M.Kes dan waktu penelitian dilaksanakan pada bulan Desember 2017 sampai dengan April 2018

\section{HASIL PENELITIAN}

Penelitian telah dilakukan terhadap 28 responden yang memenuhi kriteria inklusi dan eksklusi yang terdiri dari dua kelompok (kelompok A sebanyak 14 responden dan kelompok B sebanyak 14 responden).

\begin{tabular}{|c|c|c|c|c|c|}
\hline \multirow[t]{2}{*}{ No } & \multirow[t]{2}{*}{ Karakteristik } & \multicolumn{2}{|c|}{$\begin{array}{l}\text { Kelompok } \\
\text { Intervensi }\end{array}$} & \multicolumn{2}{|c|}{$\begin{array}{c}\text { kelompok } \\
\text { Kontrol }\end{array}$} \\
\hline & & $\mathbf{n}$ & $\%$ & $\mathbf{n}$ & $\%$ \\
\hline \multirow[t]{3}{*}{1} & Umur & & & & \\
\hline & $<20$ th & 1 & 7,1 & 4 & 2,6 \\
\hline & $20-35$ th & 13 & 92,9 & 10 & 71,4 \\
\hline \multirow[t]{7}{*}{2} & Pendidikan & & & & \\
\hline & SD & 0 & 0 & 2 & 14,3 \\
\hline & SMP & 4 & 28,6 & 3 & 21,4 \\
\hline & SMA & 7 & 50,0 & 5 & 35,7 \\
\hline & Diploma & 2 & 14,3 & 4 & 28,6 \\
\hline & Perguruan & 1 & 7,1 & 0 & 0 \\
\hline & Tinggi & & & & \\
\hline \multirow[t]{4}{*}{3} & Pekerjaan & & & & \\
\hline & IRT & 8 & 57,1 & 7 & 50,0 \\
\hline & PNS & 2 & 14,3 & 2 & 14,3 \\
\hline & Swasta & 4 & 28,6 & 4 & 35,7 \\
\hline \multirow[t]{4}{*}{4} & Paritas & & & & \\
\hline & Primigravida & 8 & 57,1 & 9 & 64,3 \\
\hline & Multigravida & 6 & 42,9 & 5 & 35,7 \\
\hline & $\begin{array}{l}\text { grande } \\
\text { multigravida }\end{array}$ & 0 & 0 & 0 & 0 \\
\hline
\end{tabular}

Tabel 5.1 Karakteristik frekuensi Responden pada kelompok Intervensi dan kelompok kontrol

Keterangan :

$\mathrm{n}=$ jumlah responden 
$\%=$ Persentase nilai jumlah responden

Tabel 1 menunjukkan bahwa berdasarkan karakteristik responden pada kelompok intervensi menurut usia ibu hamil sebagian besar berumur 20 - 35 tahun sebanyak 13 orang (92, 9\%). Berdasarkan tingkat pendiidkan separuh ibu hamil berpendidikan SMA sebanyak 8 orang $(57,1 \%)$. Berdasarkan pekerjaan separuh ibu hamil adalah ibu rumah tangga sebanyak 8 orang $(57,1 \%)$. Berdasarkan paritas sebagian besar adalah seorang primigravida sebanyak 8 orang $(57,1 \%)$. Sedangkan pada kelompok kontrol, berdasarkan umur ibu hamil lebih dari separuh berumur $20-35$ tahun sebanyak 10 orang $(71,1 \%)$. Berdasarkan tingkat pendidikan separuh ibu hamil adalah SMA sebanyak 5 orang $(35,7 \%)$. Berdasarkan pekerjaan separuh ibu hamil adalah ibu rumah tangga sebanyak 7 orang $(50,0 \%)$. Berdasarkan paritas atau jumlah anak sebagian besar ibu hamil adalah seorang primigravida sebesar 9 orang $(64,3 \%)$.

\begin{tabular}{|c|c|c|c|c|c|c|}
\hline \multirow{3}{*}{$\begin{array}{c}\text { Pemijata } \\
\text { n } \\
\text { Perineu } \\
\text { m }\end{array}$} & \multicolumn{4}{|c|}{ Ruptura Perineum } & \multirow{2}{*}{\multicolumn{2}{|c|}{$\begin{array}{c}\text { Total } \\
\text { Jumlah }\end{array}$}} \\
\hline & \multicolumn{2}{|c|}{$\begin{array}{c}\text { Tidak } \\
\text { Ruptura }\end{array}$} & \multicolumn{2}{|c|}{ Ruptura } & & \\
\hline & $\mathbf{f}$ & $\%$ & $\mathbf{F}$ & $\%$ & f & $\%$ \\
\hline Intervensi & $\begin{array}{l}1 \\
2\end{array}$ & $\begin{array}{c}85, \\
7\end{array}$ & 2 & $\begin{array}{c}14 \\
3\end{array}$ & $\begin{array}{l}1 \\
4\end{array}$ & $\begin{array}{c}10 \\
0\end{array}$ \\
\hline Kontrol & 5 & $\begin{array}{c}35 \\
7\end{array}$ & 9 & $\begin{array}{c}64 \\
3\end{array}$ & $\begin{array}{l}1 \\
4\end{array}$ & $\begin{array}{c}10 \\
0\end{array}$ \\
\hline Jumlah & $\begin{array}{l}1 \\
7\end{array}$ & & $\begin{array}{l}1 \\
1\end{array}$ & & $\begin{array}{l}2 \\
8 \\
\end{array}$ & \\
\hline
\end{tabular}

Nilai $p=0,02$

Tabel 5.2 Pengaruh Pemijatan Perineum Selama Masa Kehamilan Terhadap Kejadian Ruptura Perineum Spontan di PMB Shinta Nur Rochmayanti, SSiT., M.Kes
Tabel 2 menunjukkan bahwa kejadian ruptur perineum lebih banyak pada kelompok kontrol 12 orang $(85,7 \%)$ yang tidak dilakukan pemijatan perineum dibandingkan pada kelompok intervensi 2 orang $(14,3 \%)$ yang dilakukan pemijatan perineum. Setelah dilakukan uji ChiSquare diperoleh nilai $p=0,02$ $(<0,05)$ maka secara statistic menunjukkan ada pengaruh pemijatan perineum pada ibu hamil terhadap kejadian rupture perineum pada saat persalinan antara kelompok intervensi dan kelompok kontrol.

Berdasarkan penelitian ini maka diperoleh karakteristik ibu hamil berdasarkan umur pada kelompok intervensi dan kelompok kontrol sebagian besar berusia $20-$ 35 tahun. Pada usia reproduktif (20 35 tahun) pada saat ini respon ibu untuk menerima pengertian tentang pemijatan perineum, manfaat dan cara pemijatan perineum lebih efektif dan dapat mempelajarinya.

Menurut Hurlock, bahwa usia reproduktif $(20-35$ tahun) terjadi kesiapan respon maksimal baik dalam menyesuaiakan hal - hal tertentu dan sedikit demi sedikit menurun seirimg dengan bertambah umur. Selain itu pada usia reproduktif mereka lebih terbuka terhadap orang laindan biasanya mereka akan saling bertukar pengalaman tentang hal yang sama yang pernah mereka alami.

Berdasarkan penelitian ini dapat dianalisis ternyata ada pengaruh pemijatan perineum pada ibu hamil terhadap kejadian rupture perineum saat persalinan antara kelompok intervensi dan kelompok kontrol, karena didaerah perineum terdapat jaringan ikat dan kolagen yang bersifat elastis maka bila 
dirangsang dengan melakukan pemijatan perineum maka akan terjadi regangan dan kontraksi pada daerah perineum sehingga aliran darah menjadi lancer dan perineum menjadi elastis. Peregangan pada perineum saat persalinan bisa mengakibatkan perubahan yang positif apabila perineum elastis, fleksibel dan lentur maka kejadian rupture perineum dapat diminimalisir atau tidak terjadi rupture perineum sama sekali (perineum utuh) dan perubahan yang negatif apabila perineum tidak elastis, fleksibel dan lentur maka regangan pada perineum akan mengakibatkan terjadi rupture perineum. Maka salah satu cara yang dilakukan untuk menghindari terjadinya rupture perineum dengan melakukan pemijatan perineum.

Hal ini membuktikan manfaat pemijatan perineum yang dapat membantu melunakkan jaringan perineum sehingga jaringan tersebut akan membuka tanpa resistensi pada saat persalinan, untuk mempermudah lewatnya bayi. Pemijatan perineum ini memungkinkan untuk melahirkan bayi dengan perineum yang utuh. Pemijatan perineum adalah teknik memijat perineum pada waktu hamil, atau beberapa minggu sebelum melahirkan guna meningkatkan aliran darah ke daerah ini dan meningkatkan elastisitas perineum akan mencegah kejadian robekan perineum maupun episiotomi.

\section{KESIMPULAN DAN SARAN}

\section{KESIMPULAN}

Kesimpulan yang dapat diambil dari penelitian ini adalah terdapat pengaruh pemijatan terhadap kejadian rupture perineum dibandingkan dengan kelompok yang tidak dilakukan pemijatan perineum selama akhir periode kehamilan

\section{SARAN}

Diharapkan melalui penelitian ini, pembaca dapat mengeksplore dan mengembangkan suatu penelitian untuk kasus dan metode yang baru di bidang kebidanan sesuai dengan kewenangan bidan dalam melakukan asuhan pada masyarakat.

\section{DAFTAR PUSTAKA}

Danuatmaja, Bonny.(2004). Persalinan Normal Tanpa Rasa Sakit. Jakarta: Puspa Swarna.

DepartemenKesehatan. (2006). Profil Kesehatan Sumatra Utara. Medan: Dinkes

(2004). Asuhan Persalinan Normal. Jakarta: Depkes.

Henderson, C. (2006). Buku Ajar Konsep Kebidanan. Jakarta: EGC.

Herdiana,Trirejeki.Dr. (2009). Tips Pijat Perineum. Liu, David.T.Y. (2008). Manual Persalinan Edisi 3. Jakarta: EGC.

IisSinsin. (2008). Seri Kesehatan Ibu dan Anak Masa Kehamilan dan Persalinan. Jakarta: Alex Media.

Indiarti. (2009). Panduan Lengkap Kehamilan, Persalinan,dan Perawatan Bayi. Yogyakarta: Diglossia Media. 
Kartika.(2008). Sehat Setelah Melahirkan. Yogyakarta: Kawan Kita Kelaten.

Liwellyin, William. (2002). Obstetri dan Genekologi. Jakarta: WidyaMedika.

Liu, David.T.Y. (2008). Manual Persalinan Edisi 3. Jakarta: EGC.

Mochtar, Rustam. Prof.Dr.MPH. (1998).Sinopsis Obstetri jilid 1. Jakarta: EGC.

Sinopsis Obstetri 2. Jakarta: EGC.Mongan, Marie F.M.Ed.M.Hy. (2007). Hypno Birthing: Metode Melahirkan Secara Aman, Mudah, danNyaman. Jakarta: BIP.

Nolan, Mary. (2004). Kehamilan dan Melahirkan. Jakarta: ARCAN.

Notoatmodjo,S.(2005).Metodologi Penelitian Kesehatan. Jakarta: RinekaCipta.

Sastroasmoro, Sudigdo. (2008). DasarDasar Metodologi Penelitian klinis. Jakarta:Sagung Seto.

Schott, J dan Priest, J. (2002).Kelas Antenatal. Jakarta: EGC.

Simkin, P danAncheta, R. (2005).Buku Saku Persalinan. Jakarta: EGC
Stoppard, Miriam. Dr. (2007). Panduan Mempersiapkan Kehamilan dan Kelahiran. Yogyakarta: PustakaBelajar.

Wiknjosastro, Hanifa. Prof.dr.DSOG. (2005).Ilmu Kebidanan. Jakarta: Yayasan Bina Pustaka Sarwono Prawirohardjo.

Whalley, Janet.RN, BSN.(2002). Panduan Praktis bagi Calon Ibu Kehamilan dan Persalinan. Jakarta: BIP.

Aidan. (2008). http://myarticlesartikelkesehatan.blogspot.com/episi otomiharuskah.html.

Amanda. (2009). http://www.rbaamandalembang.co m/article\&idhttp://www.klikdokter. com/article/detail/97

Erliana.(2009).http://perawatpsikiatri.blo gspot.com.2009/03/perineum-luka perineum-episiotomi.html

Erliana.

(2009).

http://stasiunbidan.blogspot.com/20 09/05/askeb-persalinan-dengan perineum-kaku.html

Soepardiman.(2006). Penantar Ilmu Bedah

Obstetri.http://www.geocities.com 